\title{
Research on Sulfide Biological Extraction Technology
}

\author{
Rui Wei \\ Weinan Normal University, Weinan, Shaanxi, 714099
}

Keywords: Research, Sulfide Biological Extraction, Technology

\begin{abstract}
In recent years, various kinds of desulphurization technologies for the biological oxidation of sulfide to elemental sulfur at home and abroad are introduced. The factors that affect the biological oxidation of sulfide to elemental sulfur are summarized, including the ratio of oxygen to sulfur, dissolved oxygen concentration, sulfide concentration, chemical oxidation, microbial species, $\mathrm{pH}$, temperature and other factors. We proposed biological oxidation desulfurization technology development prospects. The technology will be desulfurization and elemental sulfur recovery and as a whole, is a safe, low-cost waste of sulfur waste technology into waste.
\end{abstract}

\section{Introduction}

Sulfide is mainly found in chemical, petrochemical, paper pulp, paper, metallurgy, textile, leather, gas and other industrial production wastewater and domestic wastewater and industrial wastewater treatment facilities. Sulfides can deteriorate water quality, such as lowering $\mathrm{pH}$, increasing total dissolved solids, decreasing dissolved oxygen concentration, and the like. At present, the biggest disadvantages of conventional physico-chemical processes for desulfurization are energy consumption, chemical agents and relatively high operating costs. In recent years the development of biological desulfurization technology is favored. Biological desulfurization process can be divided into two categories: one type of final oxidation of sulfide to sulfate; the other type of sulfide is only oxidized to elemental sulfur, the final oxidation of the sulfate; the other is only sulfide oxidation of elemental sulfur, Biological oxidation of elemental sulfur biological desulfurization process also has the following advantages:

(1) a reduction in the amount of chemical reagents; (2) a small amount of sludge; (3) a reduction in the production of phytonates; (4) high sulfide removal efficiency and fast reaction rates; 6) The construction cost is low; 7) The by-products add added value to the production; 8) The production is carried out under normal temperature and atmospheric pressure with a simple process and continuous operation.

Because of its toxicity, corrosiveness, bad smell and high oxygen consumption, China has strict requirements on sulfide emission. Therefore, the oxidation of sulfide to elemental sulfur not only controls the emission of sulfide into the environment, but also realizes Sulfur recycling, in line with China's national conditions. This article will introduce the domestic and foreign research status of sulfide biological oxidation desulfurization technology, analysis of several factors that affect the desulfurization process of biological oxidation of sulfide to elemental sulfur.

\section{The Effect of Factors Sulfide Biological Oxidation}

Studies have shown that sulfides to sulfates to go through two stages: the first phase of sulfide oxidation of elemental sulfur; the second phase of elemental sulfur further oxidation of sulfites. Among them, the second stage is faster than the previous stage, the sulfide released two electron beam, polymer sulfide formation. When the concentration of 02 is low and the sulfide concentration is more than lomg / L, $10 \%$ is converted to sulfuric acid: when the sulfide concentration is greater than $20 \mathrm{mg} / \mathrm{L}$, only W50 is converted to sulfuric acid even at high oxygen concentrations. The main products of the system are thiosulfate and elemental sulfur. When $02 \mathrm{~S} / 2$ is greater than 1.0, the main product is sulfate. When $02 / 52$ is $0.6-1.0$, the elemental sulfur product is the highest, Not the enemy / 52 a 0.5 , the highest elemental sulfur products, because of thiosulfate generation. When 
the $\mathrm{S} / \mathrm{O}$ ratio is 0.6 to 1.0 , the maximum $(73 \% \pm 10 \%)$ is $0 \mathrm{~S}$. When the dissolved oxygen is too low, the chemical oxidation is the main reason for the generation of thiosulfate, when the CoZ (dissolved oxygen concentration) $<0.1 \mathrm{mg} / \mathrm{L}, 50$ : and s Chou a two have to produce. It can be seen that it is important to control the $\mathrm{S} / \mathrm{O}$ ratio in the optimal production of elemental sulfur. In the case of a certain amount of oxygen, as the concentration increases, the microorganisms do not have enough oxygen to completely oxidize the sulfides. The input of excess oxygen will convert a large amount of elemental sulfur generated into sulfate. From the influence of dissolved oxygen on the results of sulfide treatment, the reasonable control of dissolved oxygen under a given influent concentration and hydraulic load is the key to the conversion of sulfide into elemental sulfur. Yao Chuanzhong et al confirmed this conclusion through experiments. According to Burisman's study, when a concentration greater than $52 \mathrm{Zmg} / \mathrm{L}$, then converted to s. , When 52 a lower than Zmg / L is converted into s hat 2 a. When the oxygen concentration is less than $6 \mathrm{mg} / \mathrm{L}$ and the sulfide concentration is greater than lomg / L, $10 \%$ of sulfate generation and less sulfate formation can confirm that sulfides or polysulfides are inhibitors and toxic in the sulfate generation mechanism of. Biusman et al. Found that in addition to the effect of sulphide influent concentration, sulphide concentration loading per unit biofilm is also a significant factor in sulphate yield. When the sulfide concentration in the reactor is increased to ZOmg / L, the effect of oxygen concentration on sulphate yield is negligible. However, the effect of oxygen concentration on sulphate yield is quite noticeable when it is less than $20 \mu \mathrm{g} / \mathrm{L}$.

$\mathrm{pH}$, temperature and the survival of microorganisms are closely related to the stability of microbial intracellular enzymes and extracellular enzymes are affected by the $\mathrm{pH}$ value. Temperature is one of the important conditions to ensure enzyme activity. According to Li Yaxin's research, the optimum $\mathrm{pH}$ value for most CSB growth is $6 \sim 8$, and for more elemental sulfur, the effluent $\mathrm{pH}$ can be controlled at $8 \sim 8.5$. The maximum recovery of sulfur in the $\mathrm{pH}$ range of the effluent is from 8.9 to 9.2, ie, the maximum $\mathrm{pH}$ value is 9.ZL `2) . According to uKen. The study of $\mathrm{n}$, in an aerobic treatment of sulfide treatment system has this reaction: $2 \mathrm{Hs}$ a $+02 \sim 25$. $+\mathrm{ZoH}$ a; 25. +302 "250 ; a +25002 a + ZH` so the rapid increase in $\mathrm{pH}$ value of the reactor biological desulfurization caused some impact on its ability to cause some desulfurization 〔6〕. Temperature is one of the important conditions to ensure enzyme activity, Ma Yanling and others from the study that when the temperature is 25 to $40{ }^{\circ} \mathrm{C}$, regardless of the inlet HZs concentration of high or low, the removal rate of $90 \%$ or more.However, when the temperature is higher than $40{ }^{\circ} \mathrm{C}$ or lower than The removal rate decreased at $25{ }^{\circ} \mathrm{C}$, especially when the temperature was higher than $40{ }^{\circ} \mathrm{C}$, the removal rate decreased obviously. The main reason was that the catalytic reaction in the biological fixed bed was accomplished by the enzymatic catalysis of microorganisms, which was sensitive to high temperature The maximum removal rate of HZS at $30{ }^{\circ} \mathrm{C}$ is consistent with the optimal temperature for the growth of Thiobacillus denitrificans, so the influence of temperature on biological desulfurization process can not be neglected. $\sim 9.0$, the temperature of $4 \sim 95{ }^{\circ} \mathrm{C}$ under the conditions of colorless sulfur bacteria growth and activity: the requirements of DO is very loose, in the high to the saturation concentration as low as the state of anaerobic, there are colorless sulfur bacteria to survive. Photosynthesis Each additional 19 bacterial cells of sulfur bacteria produce 1-29 elemental sulfur and grow and move Exposure to light poses difficulties for reactor design and increases operating costs; some species also store sulfur in the body; the rate and capacity of oxidation are limited by the growth rate and total amount of bacterial cell material. Suitable for the biological desulfurization process.Because of CeesBiusman et al in the study of biological oxidation and chemical oxidation of sulfide in waste water, the biological oxidation process was significantly faster than the catalyst-free chemical oxidation rate. When the sulfide concentration of 150mg / L, the biological The rate of oxidation is seven times faster than the rate of chemical oxidation without catalyst. When the concentration of sulfide is $10 \mu \mathrm{g} / \mathrm{L}$, the rate of biological oxidation is 75 times of the rate of chemical oxidation without catalyst.

In the study of biological desulfurization, the most widely used microorganisms at home and abroad are the three kinds of colorless sulfur bacteria, photosynthetic sulfur bacteria and 
denitrifying bacteria. According to Robertson's research on the chromosomal sulfur bacteria, most of the chromophilic sulfur bacteria use 02 (or N03) as an electron acceptor and emit sulfur in vitro, so the rate and capacity of oxidation are not limited by cell growth. According to the study by Kuenen et al., It has been found that when the nutrients are limited and there are enough sulfides, the colorless sulfur bacteria can efficiently oxidize sulfur compounds and extracellular elemental sulfur with little or no obvious growth. Colorless sulfur bacteria have a high oxidative capacity of at least 209 elemental sulfurs per 19 bacterial cells. And research has shown that a wide range of environments can be living in colorless sulfur bacteria, in the $\mathrm{PIH} . . \sim 9.0$, the temperature of $4 \sim$ $95{ }^{\circ} \mathrm{C}$ under the conditions of all have colorless sulfur bacteria growth and activity: the requirements of the DO is very loose, in the high to the saturation concentration as low as the complete state of anaerobic, there are colorless sulfur bacteria to survive. For each additional 19 bacterial cells, photosynthetic sulfur bacteria produce l-29 elemental sulfur and require light for growth and activity, posing difficulties for reactor design and increasing operating costs; some species also store sulfur in the body; and oxidation rates and capacities are affected Restriction of bacterial cell material growth rate and total amount. It can be seen, colorless sulfur bacteria more suitable for biological desulfurization process.

\section{The Prospects of Biological Oxidation Desulfurization Technology}

From the current research point of view, the new process of biological oxidation of sulfur dioxide desulfurization is turning waste into treasure management approach, the elemental sulfur generation increases the added value and the sulfur recycling, and gradually replace the traditional treatment methods and become zero emission control process. Biological desulfurization technology is more gentle, low energy consumption, less investment, small footprint, high efficiency, stable and safe operation, has broad prospects. Our country lags far behind foreign countries in the study of this new technology. The utilization of the diversity of the species is also very limited, confined to the colorless sulfur bacteria and Thiobacillus thiophate, photosynthetic bacteria involved very little. And anaerobic methods rarely studied. Sulfide biological oxidation desulfurization is almost still in the experimental stage. In the future, we must make full use of the advantages of our rear-power forces to learn the essence and be bold in innovation so as to develop a sustainable and environmentally-friendly response. Therefore, the research and application of biological oxidative desulfurization should pay attention to the following aspects: (1) To develop a well-designed reactor; to achieve the separation of the components to achieve high efficiency, continuous flow, and extension of the flow effect of stable requirements, to achieve industrial amplification. (2) Utilizing the knowledge of biotechnology and genetic engineering to improve the activity, stability and selectivity of bacteria, broaden the scope of application, carry out large-scale research on application of composite microbial desulfurization technology and research on multi-bacteria and multiphase reactors. (3) Anaerobic bacteria desulfurization research to be developed. (4) How to make it easier for microorganisms to metabolize the products of sulfur to separate from the reaction phase or fix the metabolites in the phase will be the problem to be solved by the microbial desulfurization technology.

\section{Conclusion}

As an important standard for the new biological desulfurization process, the following are listed: (1) reduction in output of non-objective sulfate; (2) reduction in power consumption (aeration); (3) simple reactor structure; (5) The dosage of chemical reagents is reduced. The authors believe that the following aspects should be emphasized in the future research and application of biological desulfurization: (1) to broaden the scope of application, to screen new strains with higher desulfurization activity and better genetic stability; (2) The development of efficient, continuous flow, extension of the flow of stable bioreactor, to achieve industrial amplification; (3) anaerobic bacteria desulfurization is still small, yet to carry out large-scale application research. In short, the biological desulfurization technology is mild, can Low consumption, low investment, broad 
prospects. With the continuous development of biotechnology and chemical engineering, biological desulfurization technology will make greater progress.

\section{References}

[1] GOMMERS P J F. Simultaneous sulfide and acetateoxidation in a denitrifying fluidized bed reactor, I. startup and reactor performance [J]. Wat Res, 1988, 22:1075- 1083.

[2] GOMMERS P J F. Simultaneous sulfide and acetateoxidation in a denitrifying fluidized bed reactor mea-sure-ments of activities and conversions [J]. Wat Res, 1988, 22: 1085- 1092.

[3] ROBERTSON L A, KUENEN J G. Anaerobic andaerobic denitrification by sulfide oxidizing bacteria fromwaste water[A]. Anaerobic Waste Water TreatmentTNO Corp Comm Dept[C]. Netherlands: [ s.n.],1983. 3- 12.

[4] STEFESS G C, JYEBEB J G. Factors influencing ele-mental sulfur production from sulfide or thiosulfate byautotrophic thiobacilli[ J]. Forum Microbiology, 1989, 12: 92- 101.

[5] BUISMAN C J. Optimization of sulfur production in abiotechnological sulfide-removing reactor [J]. BiotechBioeng, 1990, 35:50- 56.[17]BUISMAN C J. Kinetics of chemical and biological sul-fide oxidation in aqueous solutions[J]. Wat Res, 1990, 24(5): 667- 671.

[6] BUISMAN C J, LETTINGA G. Sulfide from anaero-bic waste treatment effluent of a papermill [J]. WatRes, 1990, 24(3): 313- 319. 